\title{
FINANCING POLICY OF FIRMS IN THE CONTEXT OF CRISIS-INDUCED VULNERABILITIES
}

\author{
Mihaela Brîndușa Tudose \\ Gheorghe Asachi Technical University of Iași \\ brindusatudose@gmail.com \\ Valentina Diana Rusu \\ Department for Interdisciplinary Research in Social Sciences and Humanities, \\ Alexandru Ioan Cuza University of Iasii \\ valentinadiana.ig@gmail.com
}

\begin{abstract}
Our study analyses the changes in the financial structure of the firms in the context of the vulnerabilities induced by the financial crisis. The study shows that there have been registered a reconfiguration of firms' financial structure which has triggered an increase in their financial fragility and vulnerability to crises. The results obtained confirm that the effects of financing differ depending on the economic conditions in particular period (normal periods and crisis periods). In tranquil times solvency is more important for the firms than liquidity. After crisis, the firms became more cautious regarding liquidity, solvency and the prospect of securing longterm financial balance. These firms have abandoned the objective of maximizing the positive effects of debt financing adopting a more prudent financing.
\end{abstract}

Keywords

financial crisis; financial fragility; financing policies; liquidity; solvency; vulnerability

\section{JEL Classification}

G32; G01

\section{Introduction}

Unlike the earlier challenges that prompted research in the field (e.g. the capital structure irrelevance or relevance), the present-day challenge consists in the manner in which firms must finance so as to cope with the imbalances (such as crises) that affect the economy. To understand how firms secure the financing of their operations, it is necessary to examine the determining factors of the financing decision. Specialist literature includes a vast body of research on this issue; encapsulating the wide-ranging debates, the determining factors of financial structure have been grouped as follows: a) firm-specific determining factors; b) industry-specific determining factor); c) countryspecific determining. Studies that explore the role of variables specific to firms, industries and countries in defining firms' financing policies suggest that the three factor categories influence differently the corporate capital structure. Under normal circumstances, firm-specific factors wield the greatest influence over capital structure. However, in cases when the society is affected by major imbalances (such as crises), the dominance of the influence of specific factors over capital structure changes. As a result, in the context of crises associated with a systemic credit crunch, the impact of macroeconomic factors becomes more extensive, causing an increase in firms' vulnerability and fragility.

Research has shown that the effects of financing and risk management differ depending on the economic conditions in particular period (normal periods and crisis periods). Moreover, the empirical studies conducted have attempted to measure the impact of 
funding shocks on corporate investment by examining the last financial crisis, viewing this as a natural research subject (Campello et al., 2010a; Campello et al., 2010b, Duchin et al., 2010; Almeida et al., 2012). These studies have focused on determining the degree to which firms anticipated the financial crisis, showing that, to the extent that firms can forecast an impending crisis, the real effects of financing can be offset before the shock. Comparing the two scenarios (anticipating the crisis or not), it has been shown that risk management mitigates funding shocks in two ways (Andersen, 2008): a) first, greater concern about the imminent onset of a financial crisis compels firms to invest more conservatively; b) second, by anticipating a higher likelihood of a crisis, firms set up monetary reserves that reduce the impact of financial shocks on investment.

The main objective of this article is to examine the dynamics of firms' financing in a crisis context in order to highlight the link between the various financial structures adopted by firms and their financial vulnerabilities. The methodology underlying the development of this article was hypothetical-deductive. By analysing and summarising the most relevant works in the field, we observed that the corporate financing focus is shifting from optimality to sustainability; under the banner of these transformations, the optimisation of firms' financial structure must no longer target only the maximisation of shareholder earnings, but should also ensure financial sustainability while minimising risks.

Our study is structured as follows: section 2 presents the coordinates of financial fragility; section 3 presents the methodology of the research; section 4 presents the analysis of the effects of financing on financial vulnerability; the last section advances some conclusions.

\section{Financial fragility}

Amid major imbalances, the increase of debt financing amplifies risks, causing firms to become more fragile from the financial perspective; conversely, internal financing (using retained earnings), being more stable and durable, entails minimal risk levels and improves financial vulnerability to crises.

The formulation of the hypothesis of financial instability as a theoretical argument of crises was prompted by the following important observations (Iancu, 2010):

a) the foundations of the modern capitalist economy there are, on the one hand, the investments in financial (capital) assets and, on the other, a sophisticated and complex financial system interconnected with the investment and the real economy processes; b) financial assets, which have the capacity to generate revenue/profit, determine firms to earmark increasing funds (including borrowed ones) for investments as they anticipate future earnings;

c) as a result of the above, there is a general tendency of the financial system to become increasingly leveraged, especially during times of prosperity, which leads to a rise in the degree of vulnerability in the context of potential crises (including in the case of potential systemic credit squeeze).

In an environment that favoured indebtedness, almost all firms end up being overindebted and face similar financing problems. Amid a systemic credit crunch, it is rarely possible to finance the firm by contracting new loans. In such a situation, solvent yet illiquid firms may be forced into bankruptcy to the extent that they are temporarily unable to meet their debt commitments (Sen, 2010). On the other hand, during periods of systemic constraints on liquidity, the odds of financing the cash flow deficit by selling the firm's assets is also limited, because other firms behave in the same way to finance their own needs. Even with a very low level of debt, firms cannot avoid the crisis, because converting assets into liquidity would not be possible. In relatively calm periods, liquidity is less important than solvency, because a solvent firm will be able to 
find financing to cover potential liquidity problems. In a crisis atmosphere, liquidity can become more important (Bernanke et al., 1988).

By correlating the grouping of units based on the Minskyan model (hedge units; speculative units; Ponzi units) with the systemic credit squeeze, recent research (Sen, 2010) has highlighted that, although a firm may be viewed as a hedge unit, a systemic credit crunch can induce financial structure fragility (which runs counter to the initial Minskyan claims). This is due to the fact that the crisis can be so severe, systemic and devastating on a global scale, that the firms' prospects of achieving target earnings would suddenly dry up.

The conclusion that emerges is that although they offer a range of advantages, debts trigger serious problems related to financial fragility compared to financing using retained earnings and own capital. In an environment of uncertainty over projected income, even though firms may have the lowest debt ratio, making debt payments at scheduled maturity can pose serious problems. Any economy that relies on uncontrolled leverage is doomed to collapse eventually. Under such circumstances, John K. Galbraith's postulate, proclaimed as early as 1958, still proves its veracity: creditdriven growth is not sustainable.

\section{Methodology of the research}

The examined sample consists of 90 companies listed on the Bucharest Stock Exchange. As for the delimitation of the period under review, we looked at the 20062011 period in order to capture the peculiarities of developments prior to and during the crisis. Information was collected from the annual financial statements (available both on the website of Ministry of Finance, in the companies information section and on the website of each company).

The current ratio reflects the potential for certain assets to be turned, over the short term, into liquidity to meet current payment obligations. One of the fundamental principles of the financial equilibrium of a company states the current assets value must be always higher than the accounts payable or current liabilities. Reference values of this indicator are: the minimum accepted value is 1 , below this level the company being at risk of default; the maximum acceptable value is 2 , above this level use of current assets being considered improper. The accounting regulations harmonised states that the recommended accepted value - of the current ratio - is around 2.

To determine solvency, we considered two categories of information: equity and total financial liabilities. Solvency restores a debtor's opportunity to have sufficient assets to be able to meet payment obligations.

In assessing the headline threshold for this indicator, we considered two further indicators:

- Debt/equity ratio - based on how it was calculated (as the ratio of medium and longterm debt and total liabilities, plus equity), it can be interpreted as the share of medium and long-term debt in the permanent capital; the minimum threshold for the solvency indicator must be 1 (equity must cover at least the financial liabilities while the other side of permanent capital should cover non-financial debt and possibly part of current assets);

- The mean share of medium and long-term debt (out of total liabilities) - provides information on the structure of working capital; when the indicator value is low, ensuring the financial stability depends primarily on the size of equity; this predetermines us to recognise same minimum threshold for solvency.

To examine the evolution of the cash-flow we relied on the French model, which accounts for the variation of net cash flow based on the interaction between long-term and short-term equilibrium, respectively, on the variation of the working capital and the working capital requirement $(\Delta \mathrm{CF}=\Delta \mathrm{WC}-\Delta \mathrm{WCR})$. 
To assess changes in net cash flow (at the end of the year compared to the beginning of the year), we collected information on the working capital and the working capital requirement. The increase in working capital is evidence of improvement in the company's financial structure, namely the increased share of stable to permanent needs. The same growth demonstrates the company's capacity to generate cash both at the top and the bottom section of the balance sheet and to improve its cash position considerably. Conversely, the decrease in working capital is evidence of a financial imbalance: permanent needs are covered with short-term resources. This situation, coupled with the increased working capital requirement, leads to chronic cash flow imbalance, respectively, to a greater risk of bankruptcy for the company.

A positive change in net cash flow is interpreted as an increase in the real capacity to finance investment. A negative variation suggests a decline in real financing investment capacity (i.e., a reduction in asset value).

Given the dependence of cash flow to the change in the working capital requirement, it is assumed that a profitable company does not necessarily have a positive cash flow, as the latter is dependent on variations in financing requirements and, furthermore, on fluctuations in making or receiving payments.

\section{Analysis of the effects of financing on financial vulnerability of Romanian companies}

Starting from the observation that in relatively quiet times, liquidity is less important than solvency (because a solvent company will be able to secure funding to cover any liquidity problems) (Sen, 2010) whereas in a crisis environment, liquidity may become more important (Bernanke et al. 1988), we aim to analyse how the two indicators (liquidity and solvency) evolved over the period 2006-2011, using as benchmark the Romanian companies listed on Bucharest Stock Exchange.

To highlight the element of originality that we aim to deliver, we should point out the following:

a) We will consider both a firm-level and an aggregate-level analysis;

b) For a representative sample of firms (non-financial firms listed on the Bucharest Stock Exchange) we will examine the current ratio in terms of the relation of current assets and short-term debt;

c) As the analysis is performed retroactively (for the 2006-2011 period), we do not use estimated values for the solvency ratio, but rather the actual recorded ratio; solvency will be measured based on the relationship between equity and total financial liabilities; d) In addition to the liquidity and solvency ratio, we will analyse the cash flow for the period to assess the financial behaviour of firms both during the pre-crisis period and during the crisis.

\section{Study results}

By processing the data we obtained a set of results, summarised in Table 1 below. The table provides the mean values of indicators, representative of the entire sample (values were obtained by determining the simple arithmetic mean of the individual values of the 90 firms in the sample). 
Table 1 Evolution of indicators in the period 2006-2011

\begin{tabular}{|c|c|c|c|c|c|c|c|c|}
\hline & Indicators & 2006 & 2007 & 2008 & 2009 & 2010 & 2011 & $\begin{array}{c}\text { Period } \\
\text { average }\end{array}$ \\
\hline \multirow{4}{*}{$\begin{array}{c}90 \\
\text { firms }\end{array}$} & Current ratio & 1.88 & 2.01 & 2.41 & 2.53 & 2.63 & 2.49 & 2,32 \\
\hline & Solvency & 9.49 & 9.09 & 14.7 & 15.02 & 13.71 & 14.28 & 12,71 \\
\hline & \multirow{2}{*}{$\begin{array}{l}\text { Net cash flow } \\
\text { change }[\Delta \mathrm{TN}] \\
(\% \text { of firms with } \\
+ \text { or }- \text { change })\end{array}$} & positive & $53.33 \%$ & $51.11 \%$ & $42.22 \%$ & $56.67 \%$ & $55.56 \%$ & $51,78 \%$ \\
\hline & & negative & $46.67 \%$ & $48.89 \%$ & $57.78 \%$ & $43.33 \%$ & $44.44 \%$ & $48,22 \%$ \\
\hline
\end{tabular}

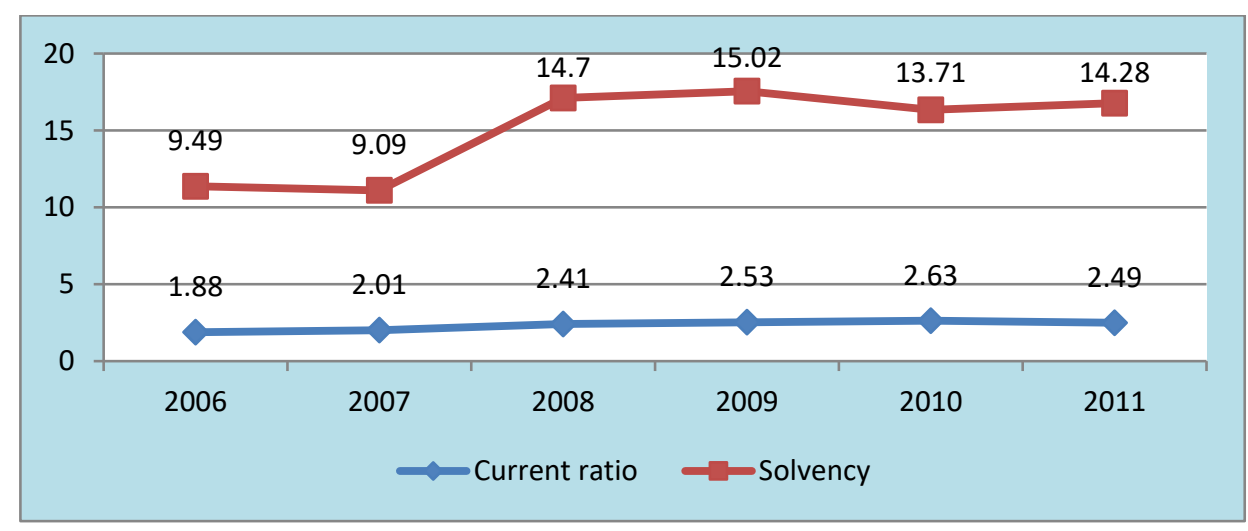

Figure 1 Evolution of liquidity and solvency in 2006-2011

By processing globally the data in the sample, we observed that the average current ratio, representative for the whole period, is 2.35. The fact that the indicator stayed around the maximum permitted value reflects a somewhat prudent current asset management policy.

The mean solvency rate over the entire period we looked at is 12.69. In terms of annual averages, one can notice an upward trend (from 9.49 and 9.06 respectively early in the period to 14.28 in the last year of the review). Indicator values reflect a good, rising level of solvency. This may be explained by the decreased share of debt financing (especially medium and long-term financing).

As regards changes in net cash flow (calculated in relation to values recorded at the beginning and end of each year), we noticed that, in the first part of the period under review, the share of companies that recorded a negative change in net cash flow increased (from $46.66 \%$ to $48.88 \%$ and $57.77 \%$; in the second half of the period, the share of firms with negative net cash flow decreased to $44.44 \%$ ).

\section{Interpretation of results}

As far as liquidity is concerned, evolutions cannot be viewed as positive because:

- the number of companies falling within the optimal range decreased (minimum 1, maximum 2);

- the number of firms that do not use assets efficiently increased;

- there was an insignificant reduction in the number firms at risk of default.

The evolution of solvency itself was not favourable either: there was a doubling of the number of companies recording solvency ratios less than one unit, translating into less equity to financial liabilities and consequently into an impairment of working capital and net cash flow, respectively. The number of firms in the other benchmark intervals varied only slightly. 
The analysis focusing on net cash flow change reveals an increase in the share of firms recording negative variation (for the first three years of the period examined), followed by a reduction (in the second part of the period).

In light of these considerations, the period under review is defined by:

- a decline of the examined indicators in the 2006-2009 interval;

- an improvement of indicators in the 2010-2011 period.

\section{Conclusions}

Amid the transformations that have marked the economic and social life, we are witnessing a reorientation of the research on corporate financing towards the study of the impact of debt financing on financial vulnerability. The old challenge (the ratio of debt in the firm's overall financing) has been abandoned in favour of a new challenge: financial fragility and vulnerability to crises.

The problems related to the way in which firms must finance their operations remain current and acute. This is due to the fact that indebtedness generates financial fragility, while the latter amplifies firms' vulnerability during crisis periods; if a fundamental change does not occur in financing behaviours (in terms of a reduction of debt dependence), the vulnerability of the financial system to crises will be heightened. The basic solution to stabilise the economy is to change firms' financing method (by reconsidering risks).

In the case of Romanian companies, the evolution of current ratio levels validates the following hypothesis: during relatively tranquil times, liquidity is less important than solvency, while in a crisis environment, liquidity may become more important (reached similar conclusions; Bernanke et al., 1988; Sen, 2010; Danso and Adomako, 2014). The slight increase of the current liquidity over the maximum level can be interpreted as the result of the firms' concerns to provide liquidity (during crisis periods).

The upward evolution of the solvency indicators indicates that firms have redefined their financial policies amid concerns to reduce financial vulnerability (by decreasing their medium and long-term debt).

The information obtained on the variation of net cash flow reveals a deterioration in long-term financial balance in the first three years of the examined period, followed by a slower recovery to the original condition (over the next three years). This movement confirms the hypothesis that during the pre-crisis period there was a general tendency towards increased leverage in the whole system (Iancu, 2010), leading to increased vulnerability. During the crisis, changes in the financing habits (in the sense of a decreasing reliance on debt) reduced the vulnerability of the system. The change in the firms' financing approach (owing to a reconsideration of risk) enabled the improvement in the situation of the companies under review (which returned to pre-crisis levels).

Considering that research in the field has expanded considerably over the years, we would like to note that, for the purposes of this study, we aimed to provide a selection of the most relevant research; hence, we acknowledge that the study does not claim to be exhaustive. Beyond these limitations, we consider that the stated opinions remain relevant. The paper serves as a starting point for conducting future, more extensive research.

\section{References}

Almeida, H., Campello, M., Laranjeira, B. A., Weisbenner, S. J. (2011), Corporate Debt Maturity and the Real Effects of the 2007 Credit Crisis, available at SSRN: http://ssrn.com/abstract=1405505 or http://dx.doi.org/10.2139/ssrn.1405505, accessed 11.03.2017. 
Bernanke, B., Campbell, J., Friedman, B. and Summers, L. (1988), Is There a Corporate Debt Crisis?, Brookings Papers on Economic Activity, Vol. 19, No. 1, pp. 83134.

Campello, M., Graham, J., Harvey, C. (2010b), The real effects of financial constraints: Evidence from a financial crisis, Journal of Financial Economics, Vol. 97, Issue 3, pp. 470-487.

Campello, M., Giambona, E., Graham, J. R, Harvey, C. R. (2010a), Liquidity Management and Corporate Investment During a Financial Crisis, Review of Financial Studies, Society for Financial Studies, Vol. 24, No. 6, pp. 1944-1979.

Danso, A., Adomako, S. (2014), The financing behaviour of firms and financial crisis, Managerial Finance, Vol. 40, No. 12, pp. 1159-1174.

Duchin, R., Ozbas, O., Sensoy, B. A. (2010), Costly external finance, corporate investment, and the subprime mortgage credit crisis, Journal of Financial Economics, Vol. 97, Issue 3, pp. 418-435.

Iancu, A. (2010), Sinteză privind modelarea fragilităţii sistemului financiar [Overview of modelling financial system fragility], Romanian Society for Economic Science, Review OEconomica, Vol. 3, pp. 161-168.

Sen, A. (2010), A without Debt and Strong Financial Structure, International Research Journal of Finance and Economics, Issue 59, pp. 77-85. 